\title{
Brief Discussion on Education Modes of Vocational School
}

\author{
Yimei Ren, Ping Ma, Xu Wang, Qian Wu
}

Base in humanities and social science of Tianjin University of Technology and Education Vocational School Affiliated to Tianjin University of Technology and Education renyimei2005@163.com

\begin{abstract}
It is more important for vocational schools to cultivate talents in process of training students' skills. The key to improve the quality of vocational education is to set up comprehensive and cultivating-talents-oriented faith and diversify talent training standards. By stimulating the students' learning motivation and creating integrated teaching environment, teachers let each individual receive attention.
\end{abstract}

Index Terms -Education mode; cultivating talents; motivation; integration; relationship between teachers and students

\section{论职业学校的教育模式}

\author{
任毅梅 ${ }^{1}$ 马平 ${ }^{2}$ 王旭 ${ }^{3}$ 吴倩 ${ }^{4}$ \\ ${ }^{14}$ 天津职业技术师范大学人文社科基地 \\ ${ }^{23}$ 天津职业技术师范大学附属技工学校
}

摘要 职业学校在培养学生技能的同时, 更重 要的是育人。提高职业教育质量的关键是教 师树立育人为本的教育信念、建立多元化的 人才培养标准。教师通过激发学生的学习动 机, 创设一体化教学情境, 建立友善的师生 关系, 满足每个学生个体成长的需要。

关键词: 教育模式 育人为本 动机 一体化 师生关系

\section{1. 引言}

教育是培养人的社会活动。就劳动对象 而言, 再也没有比人更为复杂的。教师劳动 对象的复杂性、多变性, 体现在教师的教育 对象是正在成长、发展中的学生。

职业教育在我国教育体系中占有半壁江 山, 约有百分之五十左右的学生接受的是职 业教育。从数量上看, 职业学校的学生是一 个十分庞大的群体。从培养质量上看, 职业 学校的学生的综合素质与社会、家长、学生 的期望还有很大的差距。职业教育在世界各 国的经济发展中均发挥着重要作用。我国是 制造业大国，从中国制造发展成为中国创造, 需要大量既懂理论又掌握技能的复合型人 才。职业学校从人才培养的性质方面看, 理 所应当成为国家培养应用型、复合型人才的 主要渠道。职业学校的教师应该怎样培养人 是一个值得认真思考的问题, 也是创新教育 模式探索的关键所在。

\section{2. 教师树立坚定的教育信念}

创新教育模式要解决的首要问题是教育 信念。教师应树立育人为本, 成人方能成才 的教育信念。

教育信念是教育者坚定信奉的教育观念 或主张。每个人所处的时代和社会地位不同, 所持的教育信念也不同。思想是行动的指南。 明确、清晰的教育理念, 决定教师的教学行 为和育人方式。

职业学校教师，特别是中职学校教师面 对的学生大部分存在学业障碍。一些学生严 重厌学，他们没有养成良好的学习习惯，不 知道怎样学习, 没兴趣读书, 教师每时每刻 都面临怎样组织教学的问题, 把在升学考试 中被普通教育筛选后剩下的学生培养成才是 对教师的挑战。职业学校的教师要成为卓越 的教师, 需要在瞬息万变的复杂的教育情境 中，随时运用生成性教育资源，使之与教学 内容融合成一体, 达到 “润物细无声” 的境 界。

长期以来, 受传统观念的影响, 我国公 众对于职业教育存在认识上的误区，导致职 业教育不被社会重视。一方面国家经济建设 急缺的技能型人才，供给严重不足; 另一方 面学业成绩名列前茅的学生多数选择接受普 通教育，接受职业教育只是少数学生无奈的 选择。学生宁可选择像过独木桥一样的普通 
教育, 也不愿意读职业学校。职业学校面临 生源严重不足、培养质量不高的现实。这种 现状成为职业教育不得不面临的发展瓶颈。

目前的升学考试制度, 培养人才的标准, 使 这种状况愈演愈烈。创新教育模式针对职业 学校面临的突出问题, 力图改变现状, 倡导 教师树立人人成才的教育信念。

教师在教育活动中起着主导作用, 规划 教育活动的方向, 管理教育活动的目标、传 递信息的内容和方式。孔子提倡“有教无类”, 首先教师要对学生充满信心。重新认识学生, 这是实现教育目标的第一步。在教育普及的 当今, 没有学不好的学生, 只有教不好的教 师。教师相信无论什么样的学生, 经过教师 的精心培养, 都可以成才。坚定的教育信念 在教师的教育活动中作用十分显著。教师相 信每个学生都有闪光点, 教师运用自己的一 双慧眼, 像伯乐发现千里马一样, 挖掘学生 的潜能。其次是教师对学生充满爱心。有爱 才有力量, 不抛弃, 不放弃。爱学生体现在 接受学生的一切, 特别是理性地面对学生成 长中表现出来的各种问题。教师根据学生的 年龄特点和心理发展特点, 灵活运用教育规 律, 晓之以理, 动之以情, 育人育心。最后 是教师育人的恒心。教育活动是一个持续的 过程。在这个过程中, 现实生活的各个方面 都会影响到教育对象—学生的成长。塑造 人的过程的漫长与复杂, 远不是一两节课、 三五日就能解决的教育问题。教育活动的挑 战也正体现于此。学生行为的反复变化、波 澜起伏, 属于常态, 教师的教育活动正是伴 随学生的成长而延续的。

\section{3. 激发学生的学习动机}

创新教育模式要解决的另一个问题是激 发职业学校学生探索未知的动机。动机是引 起个体活动, 维持这种活动朝着某一目标进 行, 以满足个体某种需要的内部动力。动机 对于学生的成才有重要影响, 从早期的学习 开始, 并持续显著地贯穿于学生的求学历程。 学习动机水平低的学生面临更大的学业困 难。

学生的学习活动是受学习动机支配的。 动机的强度对学生的学习效果产生直接影 响。火车没有动力无法奔驰, 学生没有学习 动力, 就不可能有积极地探索未知的行为。
影响学生动机形成的因素有家庭因素, 有社会因素和学校因素。教育活动是一种有 目的、有计划地对学生施加影响的活动。学 校教育活动是通过教师进行的, 教师在学生 动机形成过程中发挥着特别重要的作用。那 些不愿意学习、不知道怎样学习的学生, 实 际上就是学习动机强度不够。

行为主义动机理论认为, 动机是某种操 作行为受到外部强化的结果。学生学习行为 形成和改变过程中, 强化环节发挥着重要作 用。适当的强化方式, 有利于激发学生的学 习动机。职业学校教师要成为激发学生学习 动机的引导人。在教育活动过程中, 教师有 意识地强化学生的学习行为, 如肯定学生的 努力、表扬学生的进步等, 都会影响学生的 学业成绩。强化的频率和强化物的数量影响 强化的效果。经常受到赞扬的学生将会增强 学习知识、提高技能、探索未知的动机, 反 之, 将会降低学生学习的动机水平。

表扬是激发学生学习动机最简单、最容 易使用也是最有效的方法。教师千万不要忘 记表扬自己的学生。学生的行为可能与教师 的期望有很大距离, 他们身上存在各种缺点 和不足。教师能否在这样的学生身上发现他 们的闪光点, 体现出教师的教育智慧。赞扬 属于强化。立即强化即发现闪光点并能在动 态的教育情境中及时给予赞扬比延迟强化效 果更佳。

及时反馈和适当评价是激发学生学习动 机的又一种有效方法。有研究表明, 反馈在 学习上的效果是十分显著的。教师在教育活 动中应当及时将学生的学习情况反馈给学 生, 使学生经常了解自己学习的结果。学生 认识到自己的进步, 可以使他们保持对学习 的热情, 并把这样的热情带入以后的学习活 动中; 及时地反馈也可以使学生发现学习过 程中存在的问题与不足, 激发上进心, 争取 更大的进步。另外, 在反馈学习结果的同时, 对其学习行为如努力程度、认真的态度等给 予适当的评价会增强反馈的促进作用。

教师营造出能激发学生学内在习动机的 学习环境十分重要。教师通过自身对事物的 兴趣、热情, 感染学生, 利用所学习材料的 新颖性和学生对新事物的好奇心激发出学生 的动机。根据学生现有的水平, 创设出难度 
略高的任务, 并不断调整任务难度水平, 保 持学生的兴趣。教师还可以通过展示学生的 作品, 强调学习过程的努力, 增强学生的完 成任务的自豪感。

\section{4. 创设丰富的、有感染力的学习情境}

创新教育模式要解决的另一个问题是创 设出富有成就的学习情境和建立良好的师生 关系。有研究院表明, 教师安排教室物理环 境的方式影响学生的学习情绪和行为。有吸 引力的情境, 如理论教学与实践教学 “一体 化” 的教学情境创设, 给学生真实工作场所 的体验, 使学生更高效, 更执着于学习任务, 实现有效教学管理。

在职业学校 “一体化” 教学的实施过程 中, 关爱的、亲密的师生关系通常可以促进 学生学习的积极性。古人云, 亲其师, 才能 信其道。环境只有通过人的因素才能发挥作 用。那些感受到教师关心的学生更愿意为完 成学习任务而付出努力。教师的行为对发展 积极的师生关系是不可缺少的, 如向学生表 明教师关注作为个体的每一位学生, 并在示 范后个别辅导学生, 欣赏和鼓励他们所付出 的努力, 对他们解决问题的方案感兴趣。另 一方面, 教师还应对学生的不良行为给予足 够的关注, 适当地表达愤怒。批评过失行为, 避免使用讽刺性语言而伤害学生的自尊心, 予以必要的惩罚来矫正学生的行为。

教育活动是师生双边的活动。教师的教 与学生的学融为一体, “润物细无声” 才是 教育追求的境界。教育活动较其他活动更富 于挑战性的原因正在于此。创新教育模式的 探索在教育活动中发挥着越来越显著的作 用。

\section{致谢}

本文为天津市教育科学规划课题 “提高 国家职教改革创新示范区高技能人才培养质 量, 创新高层次双师型职教师资培养模式研 究”（VE2003）的部分成果; 天津职业技术 师范大学科研基金 “国家级示范职业学校建 设”（HX13087）的部分成果。

本项研究得到天津市普通高等学校人文 社会科学重点研究基地: 师范能力与职业能 力研究中心资助。

\section{References}

[1]GuMingyuan., The Education Dictionary, Shanghai: Shanghai Educational Publishing House.1990.

[2]YinGuoen etc. Non-intelligence factors and the way to Cultivate [M].Hangzhou: Zhejiang people's publishing house.1996, 11

[3]Rainbird.H. Workplace Learning in Context [M].Beijing: Foreign Language Teaching and Research Press.2011, 3 